\title{
Undifferentiated Stromal Sarcoma
}

National Cancer Institute

\section{Source}

National Cancer Institute. Undifferentiated Stromal Sarcoma. NCI Thesaurus. Code C53994.

An infiltrating high grade mesenchymal tumor arising from the uterine corpus, cervix, vagina, and the ovary. 